\title{
Relationship of value of teeth color with skin color in Makassar tribe
}

\author{
Eri H. Jubhari", Wahipa Wiro, Sinaryanti
}

\section{Abstract}

Objective: This study aim to determine the relationship between teeth color value and skin color value of the Makassar tribe.

Material and Methods: This observational analytic research employs cross-sectional study and purposive sampling methods, with 73 samples; held in May 2012 in Bontoramba, Jeneponto district, South Sulawesi, Indonesia. It uses the Vita-Lumina shade guide for teeth color tests and Garnier FD344110.122.007 for skin color tests.
Results: The results show that the distribution of teeth colour value in respondents is mostly in the highest values (A1, B1, A2, B2 color) which were $71.2 \%$, while the skin value is mostly in a dark skin color (78.1\%). Data was analyzed by the chi-square test. It was found that teeth color value was not related to skin color value in the Makassar tribe ( $p>0.05$ ). Conclusion: Skin color value was not an indicator in determining the teeth color in the Makassar tribe.

Keywords: Teeth value, Skin value, Makassar tribe

Cite this Article: Jubhari EH, Wiro W, Sinaryanti. 2018. Relationship of value of teeth color with skin color in Makassar tribe. Journal of Dentomaxillofacial Science 3(1): 24-27. D0I: 10.15562/jdmfs.v3i1.446

Department of Prosthodontics, Faculty of Dentistry, Hasanuddin University, Makassar, Indonesia
*Corresponding to: Eri H. Jubhari, Department of Prosthodontics, Faculty of Dentistry, Hasanuddin University, Makassar, Indonesia erihjubhari@gmail.com

Received: 13 March 2017 Revised: 7 November 2017 Accepted: 14 January 2018 Available online: 1 April 2018

\section{Introduction}

Following developments in prosthodontics, aesthetics becomes a major factor in either replacing or repairing teeth to their natural condition. ${ }^{1,2}$ Teeth color becomes crucial when patients need dentures for prosthetic treatment or anterior tooth restoration for aesthetic purposes ${ }^{3,4}$ Some factors, such as age, gender, and skin color play an important role in choosing dentures. Methods have been suggested to evaluate the appropriate aesthetic factors when choosing dentures for edentulous patients in white skin population. ${ }^{5}$

Many experts thought that face skin color is the most appropriate guide to choosing artificial teeth color. Some said that subjects with bright or white face skin have brighter teeth, which suits to their face skin color. It is also reported that subjects with dark skin generally have darker teeth, which is suitable with their face skin color, ${ }^{5}$ therefore face skin color value influences teeth color value. Pale teeth in a white skin patient mouth will look darker while darker teeth in a dark skin patient mouth will be seen as paler than what is expected. ${ }^{1}$

In deciding tooth color, it is important to understand the Munsell Color System which is divided into three parameters; hue, chroma and value. Hue is the color dimensions that differs one type of color from the other colors (red, yellow, blue, etc). Chroma is the color dimension that describes saturation, intensity or strength of hue, while value is color dimensions that shows level of darkness or brightness. $^{6}$
Development of new materials and techniques in dentistry requires thoughtful professionals to develop the new artistic skill. The material and technique development will help dentist easily manipulate the light, color, shadow and pattern to produce realistic aesthetics. ${ }^{6,7}$

This study aims to determine the relationship between teeth color value with skin color value of the Makassar tribe.

\section{Material and Methods}

This observational analytic research, which employed cross-sectional study, was held in subdistrict Bontoramba, Jeneponto district, South Sulawesi, Indonesia in May 2012. This location was chosen because the majority of its population originally belonged to the Makassar tribe. Using purposive sampling, the samples were based on the following criteria: A. having Makassarese parents, B. being between 15 to 50 years old, C. having anterior teeth which are left or right central incisivus of the upper jaw, D. having no caries, restoration, stain, plaque, or calculus. Before data is collected the teeth must be cleaned using a manual scaller. Sample consisted of 73 subjects and was determined by estimating the proportion of the population.

After obtaining approval from local government, the subjects were instructed to fill in informed consent before being examinated and interviewed using a questionnaire. The result of dental examination was checked with shade guide Vita-Classical 
(Vitapan Classical) which consisted of the highest value (A1, B1, A2, B2), high value (C1, D2, A3, D4), medium value (B3, B4, C2, D3), and low value (A3.5, C3, A4, C4). Skin color was matched with the color of patient's using Garnier Skin Test (FD344 1 10122007) which consisted of 16 colors namely white skin value $(1,2,3,4)$, white/tan $(5,6,7,8)$, $\tan (9,10,11,12)$, and dark $(13,14,15,16)$. Data was presented in a table and statistically analyzed by using the chi square test $(\mathrm{p}<0.05)$.

\section{Results}

Table 1 shows that the most common occupation type were farmers, made up of 15 people $(20.5 \%)$, while the least common occupation type were police and drivers, which was one respondent for each occupation (1.4\%). This is expected because most of population in Bontoramba work as farmers. Most respondents (46) were female (63.0\%),

\section{Table 1 Distribution of respondent's occupation in Subdistrict} Bontoramba, Jeneponto Regency in 2012

\begin{tabular}{lcc}
\hline Occupation & Number (n) & Percentage (\%) \\
\hline Civil servant & 7 & 9.6 \\
Police & 1 & 1.4 \\
Honorer & 3 & 4.1 \\
Trader & 4 & 5.5 \\
College student & 4 & 5.4 \\
Student & 14 & 19.2 \\
Entrepreneur & 12 & 16.4 \\
Driver & 1 & 1.4 \\
Farmer & 15 & 20.5 \\
Housewife & 9 & 12.3 \\
Unemployed & 3 & 4.1 \\
Gender & & \\
Male & 27 & 37.0 \\
Female & 46 & 63.0 \\
\hline
\end{tabular}

Table 2 Distribution of respondents' of teeth value

\begin{tabular}{lcc}
\hline Teeth value & Number (n) & Percentage (\%) \\
\hline Highest value (colorA1,B1,A2,B2) & 52 & 71.2 \\
High value (color C1,D2,A3,D4) & 8 & 11.0 \\
Medium value (color B3,B4,C2,D3) & 6 & 8.2 \\
Low value (color A3.5,C3,A4,C4) & 7 & 9.6 \\
Total & 73 & 100.0 \\
\hline
\end{tabular}

\section{Table 3 Distribution of skin value of the respondents}

\begin{tabular}{lcc}
\hline Teeth value & Number (n) & Percentage (\%) \\
\hline White $(1,2,3,4)$ & 0 & 0 \\
White/Tan $(5,6,7,8)$ & 2 & 2.7 \\
Tan $(9,10,11,12)$ & 14 & 19.2 \\
Dark $(13,14,15,16)$ & 57 & 78.1 \\
Total & 73 & 100.0 \\
\hline
\end{tabular}

while only 27 respondents (37.0\%) were males. This is due to the female population being higher than the male population based on the demographic census in Bontoramba District in 2012.

Table 2 shows that most of respondents' teeth values were distributed in the highest value with 52 samples $(71.2 \%)$, while the least was in medium value with only 6 subjects $(8.2 \%)$. This is due to most respondents in this study being females and therefore, not smoking or consuming alcohol and drugs.

Table 3 demonstrates that the highest number of skin color was dark skin with 57 respondents (78.1\%), while The lowest would be white $(1,2$, 3 , 4) with $0 \%$ followed by white/tan with $2.7 \%$. This corresponds with the typical occupation of population in Bontoramba, Jeneponto Regency, South Sulawesi. Most respondents are farmers and spend the majority of the day exposed to ultraviolet light.

The score of chi square test, shown in table 4 , shows the $\mathrm{p}$-value was 0.313 or $\mathrm{p}>0.05$, and therefore shows no correlation between teeth value and gender of the Makassar tribe in Bontoramba, Jeneponto Regency, South Sulawesi.

The score of chi square test in table 5 shows $\mathrm{p}$-value is 0.058 or $\mathrm{p}>0.05$, and therefore there is no correlation between teeth value and age group of the Makassar tribe in Bontoramba, Jeneponto Regency, South Sulawesi. This was due to the physiological alteration of teeth color during the aging process and deposition of secondary dentin and reparative dentin, which further causes color alteration to teeth. It makes teeth darker and reduces pulp color effect and therefore results in a reverse correlation between teeth color value with skin color value. Someone with dark skin color tends to have brighter teeth.

\section{Discussion}

The most common occupation type was reported as a farmer $(20.5 \%)$, which was due to the fact that the majority of population in Bontoramba work as farmers. In addition, there are 3 other major occupations namely student, entrepreneur and housewife. The number of females $(50.85 \%)$ was more than males and corresponds to the demographic census in Bontoramba in 2012. ${ }^{8}$

The most distribution of respondent's teeth value is in highest value (71.2\%) because respondents in this study were mainly farmers that are exposed to ultraviolet light that leads to darker skin. People with dark skin color tend to have dark color teeth (highest or high teeth value). ${ }^{9}$ The distribution of dark skin value is $78.1 \%$, while white/tan skin is $2.7 \%$. 
Table 4 Distribution of teeth value based on gender of respondents

\begin{tabular}{|c|c|c|c|c|c|c|c|c|c|c|c|}
\hline \multirow[b]{3}{*}{ Gender } & \multicolumn{8}{|c|}{ Teeth Value } & & & \multirow{3}{*}{$\begin{array}{c}\text { Chi Square } \\
\text { test }\end{array}$} \\
\hline & \multicolumn{2}{|c|}{$\begin{array}{c}\text { Highest value (color } \\
\text { A1,B1,A2, B2) }\end{array}$} & \multicolumn{2}{|c|}{$\begin{array}{c}\text { High value(color } \\
\text { C1,D2,A3,D4) }\end{array}$} & \multicolumn{2}{|c|}{$\begin{array}{c}\text { Medium value (color } \\
\text { B3,B4,C2,D3) }\end{array}$} & \multicolumn{2}{|c|}{ 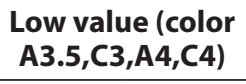 } & \multicolumn{2}{|c|}{ Total } & \\
\hline & $\mathbf{n}$ & $\%$ & $\mathbf{n}$ & $\%$ & $\mathbf{n}$ & $\%$ & $\mathbf{N}$ & $\%$ & $\mathbf{n}$ & $\%$ & \\
\hline Male & 18 & 34.6 & 5 & 62.5 & 1 & 16.7 & 3 & 42.9 & 27 & 37.0 & \\
\hline Female & 34 & 65.4 & 3 & 37.5 & 5 & 83.3 & 4 & 57.1 & 46 & 63.0 & $\mathrm{p}=0.313$ \\
\hline Total & 52 & 100 & 8 & 100 & 6 & 100 & 7 & 100 & 73 & 100 & \\
\hline
\end{tabular}

Chi-square test with $\mathrm{p}=0.313$

\section{Table 5 Distribution of age group with teeth value}

\begin{tabular}{|c|c|c|c|c|c|c|c|c|c|c|c|}
\hline \multirow{3}{*}{$\begin{array}{l}\text { Age group } \\
\text { (Years) }\end{array}$} & \multicolumn{8}{|c|}{ Teeth Value } & & & \multirow[b]{3}{*}{ Chi Square } \\
\hline & \multicolumn{2}{|c|}{$\begin{array}{c}\text { Highest value } \\
\text { (color A1,B1,A2, B2) } \\
\end{array}$} & \multicolumn{2}{|c|}{$\begin{array}{c}\text { High value(color } \\
\text { C1,D2,A3,D4) }\end{array}$} & \multicolumn{2}{|c|}{$\begin{array}{c}\text { Medium value } \\
\text { (color B3,B4,C2,D3) } \\
\end{array}$} & \multicolumn{2}{|c|}{$\begin{array}{l}\text { Low value (color } \\
\text { A3.5,C3,A4,C4) }\end{array}$} & \multicolumn{2}{|c|}{ Total } & \\
\hline & $\mathbf{n}$ & $\%$ & $\mathbf{n}$ & $\%$ & $\mathbf{N}$ & $\%$ & $\mathbf{n}$ & $\%$ & $\mathbf{n}$ & $\%$ & \\
\hline $15-20$ & 18 & 34.6 & 0 & 0 & 0 & 0 & 0 & 0 & 18 & 24.7 & \\
\hline $21-26$ & 11 & 21.2 & 1 & 12.5 & 0 & 0 & 2 & 28.6 & 14 & 19.2 & \\
\hline $27-32$ & 9 & 17.3 & 3 & 37.5 & 1 & 16.0 & 1 & 14.3 & 14 & 19.2 & \\
\hline $33-38$ & 6 & 11.5 & 2 & 25.0 & 2 & 33.0 & 0 & 0 & 10 & 13.7 & $\mathrm{p}=0.058$ \\
\hline $39-44$ & 4 & 7.7 & 1 & 12.5 & 1 & 16.0 & 1 & 14.3 & 7 & 9 & \\
\hline $45-50$ & 3 & 5.8 & 1 & 12.5 & 2 & 33.0 & 2 & 28.6 & 8 & 11.0 & \\
\hline$>51$ & 1 & 1.9 & 0 & 0 & 1 & 0 & 1 & 14.3 & 2 & 2.7 & \\
\hline Total & 52 & 100 & 8 & 100 & 6 & 100 & 7 & 100 & 73 & 100 & \\
\hline
\end{tabular}

Chi-square test with $\mathrm{p}=0.058$

The chi square test the $\mathrm{p}$-value is 0.313 or $\mathrm{p}>0.05$ therefore there is no correlation between teeth color value and gender in the Makassar tribe. This supports previous claims that there is no significant correlation between gender and teeth color. $^{5}$

Described in the anterior aesthetic theory, age and gender only interrelated with respect to the form of teeth. Females tend to have round teeth, translucent incisal edge, clearly visible incisal embrasure and a smooth surface. Male teeth are characteristically angular and rugged, with unclear and square incisal embrasure ${ }^{6}$ tooth form normally can change due to the aging factor. Someone who is getting older has attrition and eroded incisal edge because it has long been used and the tooth tubercle is lost. In addition, the long of clinic crown also increases. $^{10}$

In this study we used 15-50 years old age standard because in general, 15 years old upper anterior teeth are already errupted and starting to form secondary dentin. Meanwhile, before 60 years old, oral hygiene is normally good and the degree of anterior tooth loss is still low, particularly the upper left or right incisivus. ${ }^{11}$ Distribution of age group and teeth value suggested that older patients seem to have teeth with lower value compared with that of younger patients, which shows p-value is 0.058 or $\mathrm{p}>0.05$. It means that there is no correlation between teeth value and age group in the Makassar tribe. This is due to physiological alteration of teeth color during aging causing thickening dentin. Secondary dentin and reparative dentin deposition result in tooth color alteration. The pulp chamber becomes smaller because of the accumulation of secondary dentin making the tooth become darker and reduces pulp color effect. ${ }^{5,7}$

The chi square score $(p=0.255$ or $p>0.05)$ shows that there is no correlation between teeth color value and skin color value in the Makassar tribe. The result confirmed the reverse relation between teeth color value and skin color value. That means someone with dark skin tends to have brighter teeth. ${ }^{5}$

The same study was also conducted ignoring the age and gender. People with tan to dark skin tend to have higher value (brighter) teeth, while people with white skin tend to have lower value (darker) teeth. ${ }^{7}$

Although there has been very few studies on the shade guide standard used in determining skin color, this study employs 16 colors which can be used in a larger spectrum of skin colors compared to other shade guides used in the cosmetic industry. The wide use of other shade guides in industry is due to its validity. However, the level of darker color explained that skin color in dark skin population is not completely given in this shade guide. 
People with a dark skin level that is not available in this skin shade guide were included into the dark category. ${ }^{7}$ The prosthodontists and endodontists contended that a dark skin person has brighter teeth, but this color is not absolute due to intrinsic and extrinsic factors which influence skin and teeth colors. ${ }^{5}$

This study showed skin color can be useful in choosing denture color in the manipulation of dentures to get a more natural effect, particularly for white or dark skin patients who lost his or her anterior teeth and value the aesthetic. ${ }^{7}$

In this study, patients with the highest (brighter) teeth value to low value teeth seem to have dark skin. This can be attributed to the Bontoramba society working mainly as farmers. Their occupation makes them exposed to ultraviolet light. Another external factor is the use of modern and traditional cosmetics that is not attended to by the society in Bontoramba resulting in darker skin.

\section{Conclusion}

That teeth color is not correlated with gender, age or skin color value of the Makassar tribe. This study suggested that it is necessary to refer to other shade guides to decide teeth color in the Makassar tribe.

\section{Acknowledgement}

The authors stated no funding to declare.

\section{Conflict of Interest}

The authors report no conflict of interest.

\section{References}

1. Zarb GA, Bolender CL, Hickey JC, et al. Buku ajar prostodonsi untuk pasien tak begigi menurut Boucher. 10th ed. In Mardjono D. Jakarta: Buku Kedokteran EGC; 2001. p. 2, 288-289.

2. Satheesh BH, Ahmed MD, Nabil AA. The tooth and skin colour interrelationship across the different ethnic groups. Int J Dent 2014;14: 6.

3. Vivek S, Vikas P, Meenakshi K, et al. A study of relationship between skin color and tooth shade value in Population of Udaipur, Rajasthan. Int J Dent Clin 2010;2: 26-29.

4. Justiawan J, Sigit R, Arief Z, et al. Performance analysis of color matching technique for teeth classification based on color histogram. J Dentomaxillofac Sci 2017;2: 95-99.

5. Esan TA, Olusile OA, Akeredolu AP. Factors influencing tooth shade selection for completely edentulous. J Contemp Dent Pract 2006;7: 81.

6. Suneel VV, Halini KKV, Gopal KC. Prevalence of tooth shade and its correlation with skin colour-a crosssectional study. J Clin Diagn Res 2016;10: 72-74

7. Jahangiri L, Reinhardt SB, Mehra VR, et al. Relationship between tooth shade value and skin color: an observasional study. J Prosthet Dent 2002;87: 149-52.

8. Sumanth KV, Ravindra CS, Kusai B, et al. Differences in tooth shade value according to age, gender and skin color: a pilot study. J Indian Prosthodont Soc 2015;15: 138-141.

9. Ruchika SS, Juan G, Farhad BN, et al. Assessing the influence of skin color and tooth shade value on perceived smile attractiveness. JADA 2009;140: 696-705.

10. Bushra G, Rizwan J, Naseer A. Relationship of facial skin complexion with gingiva and tooth shade on smile attractiveness. J Interdiscipl Med Dent Sci 2016;4: 205.

10. Heinlein WD. Anterior teeth: esthetic and function. J Prosthet Dent 1980;44: 389-393.

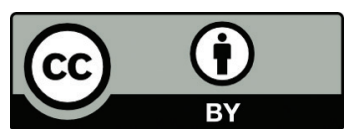

This work is licensed under a Creative Commons Attribution 